\title{
Type and Toxicity of Pesticides Sold for Community Vector Control Use in the Gambia
}

\author{
M. W. Murphy, ${ }^{1}$ W. T. Sanderson, ${ }^{2}$ M. E. Birch, ${ }^{3}$ F. Liang, ${ }^{3}$ E. Sanyang, ${ }^{4}$ \\ M. Canteh, ${ }^{5}$ T. M. Cook, ${ }^{1}$ and S. C. Murphy ${ }^{1}$ \\ ${ }^{1}$ Department of Environmental and Occupational Health, University of Iowa, Iowa City, Iowa 52242, USA \\ ${ }^{2}$ Department of Epidemiology, The University of Kentucky, Lexington, Kentucky 40508, USA \\ ${ }^{3}$ Division of Applied Research and Technology, National Institute for Occupational Safety and Health, \\ Centers for Disease Control and Prevention, Cincinnati, OH 45226, USA \\ ${ }^{4}$ University of The Gambia, Serrekunda, Gambia \\ ${ }^{5}$ The Gambia National Environmental Agency, Banjul, Gambia
}

Correspondence should be addressed to M. W. Murphy, mmurphy@cdc.gov

Received 30 November 2011; Accepted 5 March 2012

Academic Editor: Wolfgang Ahrens

Copyright ( 2012 M. W. Murphy et al. This is an open access article distributed under the Creative Commons Attribution License, which permits unrestricted use, distribution, and reproduction in any medium, provided the original work is properly cited.

\begin{abstract}
Objectives. The objective of this study was to identify the types of pesticides in circulation at local markets in The Gambia and to determine the proportion of products that were sold as unlabeled pesticides. Methods. One hundred twenty-eight samples sold as pesticides were collected from four local markets throughout The Gambia. Pesticides in the samples were identified by gas chromatography with mass spectrometry (GC/MS). Findings. Of the 128 samples collected, 115 were unlabeled. Pesticide components in 111 of those unlabeled samples were identified. Approximately $28 \%$ of these samples that contained pesticides are banned or restricted in the United States, and about 16\% was classified as hazardous by WHO. Conclusions. Based on results for 128 samples, a significant percentage of the pesticide products sold at local markets in The Gambia in 2005 are considered extremely hazardous.
\end{abstract}

\section{Introduction}

Diseases transmitted by insect vectors are a major health concern throughout the world and result in millions of deaths each year [1]. African nations are at a higher risk for vectorborne diseases than nations such as the United States, due to the tropical climate which allows disease transmission to occur year round, as well as housing conditions and lifestyles that result in greater contact with vectors. In addition, African nations often have insufficient infrastructure and are lacking the financial resources necessary for maintaining effective national vector control and drug distribution programs [2].

Application of pesticides is a simple vector control method that individuals can afford and is often the only option available to a household seeking to prevent vectorborne diseases in developing nations. However, the use of pesticides to prevent vector-borne diseases does not come without consequences. Studies have shown that human illness and death due to occupational and accidental pesticide exposures are significant health issues throughout the world $[3,4]$. From the studies conducted, there is evidence showing that chronic health effects can result from long-term pesticide exposure in developing nations $[5,6]$. High levels of pesticide exposure can result in fatal poisonings.

Occupational exposures to pesticides may cause acute and long-term health effects [7]. In 1990, WHO estimated that there were at least one million serious accidental poisonings and an additional two million people hospitalized for voluntary ingestion of pesticides each year. Pesticide exposures resulted in over 220,000 deaths worldwide. The actual number of accidental pesticide poisonings could reach as high as 25 million cases in developing nations each year if estimates for mild and unreported cases were included $[8,9]$. Pesticide-related illnesses in developing countries have not been considered a high priority by public health officers 
largely due to the lack of reliable data on pesticide exposures and use $[10,11]$.

Local communities must often take action to protect themselves from disease vectors. Most individuals purchase pesticides from pesticide vendors, individuals without an actual store, who travel to local street markets to sell pesticides along the road. These pesticides are generally affordable for the local population but with limited regulation; the quality of substances being sold as pesticides is unknown. The concerns with obtaining pesticides from unregulated sources are that the products being sold may be of poor quality, or they may not actually be pesticides and therefore will not control the vectors. Some of the products sold kill vectors effectively, but they may be highly toxic and dangerous for home use by individuals. Another concern is that the pesticides purchased may not have labels so the individual will not know what pesticide is being used, how to properly mix and apply the pesticide, and how to protect themselves and their families during use.

The objective of this research was to evaluate potential health risks due to the sale and distribution of vector control pesticides at local street markets. Specifically, this research identified pesticides being sold and whether they were appropriate for vector control activities. It also determined the proportion of pesticides samples that were sold without labels. To our knowledge, there have been no published studies that have identified the types of pesticides sold and used in local communities in The Gambia.

\section{Materials and Methods}

2.1. Study Population. This study was conducted in four locations in The Gambia, West Africa from July, 2005 to November, 2005. The four main locations involved in the research included the towns of Kuntaur, Brikama, Farafenni, and Serrekunda. These towns were selected as the major locations of street markets, also known as lumos, regarding pesticide commerce. The towns represent different geographic regions and population densities. Kuntaur was the most rural site located in the northern region of The Gambia. Farafenni is a mid-size town in the central region of The Gambia surrounded by agricultural fields. Brikama is a larger town located in western Gambia. The largest city in the country is Serrekunda, which is an urban area. By collecting samples from the four major street markets where pesticides were commonly purchased, this study investigated what was actually being sold and used as pesticides in the communities.

2.2. Sample Collection. To collect the pesticide samples, one sample of each type of product identified by a vendor as a pesticide was purchased. Samples were purchased from all pesticide vendors present at the market. The interviewers asked each vendor to sell them pesticides for killing mosquitoes and insects that might cause disease around their home. Multiple pesticides were purchased from the same vendor if they were considered different types. Pesticide samples were collected at each location over two different
TABLE 1: GC-MS operating conditions for analysis of pesticide samples.

\begin{tabular}{ll}
\hline GC/MS parameter & Component or setting \\
\hline Gas chromatograph & Agilent $6890 \mathrm{~N}$ \\
Mass detector & Agilent 5973 \\
Column & HP-5MS $(30 \mathrm{~m} \times 0.25 \mathrm{~mm}$ id, $0.25 \mu \mathrm{m})$ \\
Carrier gas & Helium \\
Purge flow and time & $25.5 \mathrm{~mL} /$ min at $1.5 \mathrm{~min}$ \\
& $1-\mu \mathrm{L}$ splitless or split with different split \\
Injection & ratios (up to $80: 1)$. Pulsed pressure \\
& injection $(40$ psi for 0.8 min) \\
Inlet temperature & $325^{\circ} \mathrm{C}$ \\
Column temperature & $40^{\circ} \mathrm{C}(2$ min $)$ \\
program & $30^{\circ} \mathrm{C} \mathrm{min}{ }^{-1}$ to $325^{\circ} \mathrm{C}$ (hold 7 min) \\
Detector temperature & $230^{\circ} \mathrm{C}$ source \\
& $150^{\circ} \mathrm{C}$ quadrupole \\
MSD transfer line & $325^{\circ} \mathrm{C}$ \\
\hline
\end{tabular}

market days in 2 ounce, wide-mouth polypropylene bottles (Fisher Scientific, Pittsburg, PA). These bottles were then packaged in expanded polystyrene containers within a box for international shipment. The samples were transported to the National Institute for Occupational Safety and Health in Cincinnati, Ohio, USA for chemical analysis.

2.3. Chemical Analysis. Pesticides were identified by gas chromatography with mass spectrometry (GC/MS). An Agilent 6890 N GC (Agilent Technologies, Palo Alto, CA, USA) equipped with a 7683 autoinjector (Agilent), split/splitless inlet, and 5973 mass selective detector operated in electron impact (EI) ionization mode was used for screening analyses of 116 samples. A mass range from $m / z=35$ to $550 \mathrm{amu}$ was recorded in full-scan mode. The GC column was operated at a constant flow of 1.3 milliliters per minute $(\mathrm{mL} / \mathrm{min})$, with a nominal inlet pressure of $9.89 \mathrm{psi}$ (average carrier gas velocity of 41 centimeters per sec $(\mathrm{cm} / \mathrm{sec})$, total flow of $29 \mathrm{~mL} / \mathrm{min}$ ). The total analysis time was 18.5 minutes. Full GC/MS operating conditions are listed in Table 1.

All samples were prepared in dichloromethane (DCM) by adding 10 microliter $(\mu \mathrm{L})$ aliquots of liquid samples or 0.5 gram (g) of solid samples to $10 \mathrm{~mL}$ DCM. In some cases, additional solutions with increased or decreased concentrations were prepared, depending on the initial MS response. A $1-\mu \mathrm{L}$ aliquot of the sample solution was injected into the GC inlet by either split or splitless injection. In the former case, different split ratios (up to $80: 1$ ) were used, depending on the sample concentration.

Full scan mass spectral data and library searching were used for compound identification. Identifications were based on a National Institute of Standards and Technology (NIST) standard library search. Specifically, if the library search gave a match factor above $90 \%$ for a given sample peak and low matches for other compounds listed in the search results, then the sample peak was identified as the compound with the high-match result. Most of the sample peaks were identified by this approach. 
TABLe 2: Analysis of pesticide samples collected from local street markets.

\begin{tabular}{|c|c|c|c|c|c|c|c|c|c|c|}
\hline \multirow{3}{*}{$\begin{array}{l}\text { Total } \\
\text { samples }\end{array}$} & \multirow{2}{*}{\multicolumn{2}{|c|}{$\begin{array}{l}\text { Labeled } \\
\text { Samples }\end{array}$}} & \multirow{2}{*}{\multicolumn{2}{|c|}{$\begin{array}{c}\text { Unlabeled } \\
\text { Samples collected }\end{array}$}} & \multirow{2}{*}{\multicolumn{2}{|c|}{$\begin{array}{l}\text { Unlabeled Samples } \\
\text { Identified by GC-MS }\end{array}$}} & \multicolumn{4}{|c|}{ Components Identified } \\
\hline & & & & & & & \multicolumn{2}{|c|}{ Single compound } & \multicolumn{2}{|c|}{ Multiple compounds } \\
\hline & $\#$ & $\%$ & $\#$ & $\%$ & \# & $\%$ & \# & $\%$ & $\#$ & $\%$ \\
\hline 128 & 13 & 10.2 & 115 & 89.8 & 111 & 96.5 & 59 & 53.2 & 52 & 46.8 \\
\hline
\end{tabular}

In some cases, the library search on a given peak found several possible compounds with similar matches (above $85 \%$ ) or the matches for the possible compounds listed were all lower than $90 \%$. Confirmed identifications for these compounds require further analytical work and results are not reported here. A relatively small number of samples were not soluble in DCM or other solvents, while others were soluble but no peaks were observed, or no library matches were found for the peaks present. Identifications for these samples could not be made.

2.4. Data Analysis. Statistical analyses were performed using SAS/STAT version 9.1 (SAS Institute Inc., Cary, NC, USA). Descriptive statistics were used to characterize pesticides identified. Likelihood Ratio Chi-Square analyses were conducted to compare the characteristics of pesticide vendors using questionnaire data. The Fisher's Exact Test was conducted in addition to Likelihood Ratio Chi-Square when cell counts were insufficient to ensure the validity of results. An $\alpha=0.05$ was selected as the Type 1 error limit so a $P$ value less than 0.05 was considered significant.

\section{Results}

A total of 128 pesticide samples were collected from street market vendors. Only $10.2 \%$ of the samples was labeled, with the majority being sold in unlabeled plastic bags or containers. The 13 pesticide samples sold in original, labeled packaging consisted of the active ingredients chlorpyrifos, endosulfan, and deltamethrin. These were not restricted for use in The Gambia $[12,13]$, though chlorpyrifos was recently banned in the United States [14]. The remainder of this study focused solely on the unlabeled pesticides sold in the street markets.

Active ingredients in 111 (96.5\%) of the unlabeled samples (Table 2) were identified. Over half of the pesticides (53.2\%) contained only one active ingredient; $32.4 \%$ contained two or three active ingredients, 9.0\% contained four to six active ingredients, and $5.4 \%$ contained seven or more ingredients. Since most pesticide formulations contain less than three active ingredients, some vendors likely blended multiple pesticides together for resale.

The pesticide components identified were primarily organophosphate (37.9\%), organochlorine (26.7\%), and carbamate chemical classes $(21.7 \%)$, with organophosphate pesticides the most abundant (Table 3 ). Permethrin pesticides were also sold at the markets. Sulfur, chlorfenson (unclassified), and metolachlor (Chloroacetanilide) were other types of pesticides that were collected.
Table 3: Chemical Classes of Pesticide Components Collected From Local Street Markets and Identified By gc-MS.

\begin{tabular}{lcc}
\hline Chemical class & \# Components & \% Total components \\
\hline Organophosphates & 61 & 37.9 \\
Organochlorines & 43 & 26.7 \\
Carbamates & 35 & 21.7 \\
Permethrins & 14 & 8.7 \\
Other & 8 & 5.0 \\
\hline
\end{tabular}

Table 4 lists all the pesticide components that were identified in the samples collected. Twenty-three different active pesticide ingredients were discovered in the samples. Chlorpyrifos, endosulfan, carbofuran, and fenitrothion were the most prevalent pesticides discovered, representing almost $56 \%$ of the total number of different pesticides. These were all common pesticides used to control disease vectors.

Sixty-nine of the pesticide components used in The Gambia are restricted or banned in the United States (Table 5). These pesticides included carbofuran, chlorpyrifos, lindane, chlorobenzilate, methyl parathion, and monocrotophos. Three types of pesticides identified (carbofuran, methyl parathion, and monocrotophos) are considered by WHO to be extremely or highly hazardous, with an additional two types of pesticides (chlorobenzilate and naphthalene) considered by WHO to be obsolete (have been previously discontinued for use as a pesticide). Lindane, chlorobenzilate, monocrotophos, and methyl parathion are also all pesticides on the United Nations PIC list requiring prior informed consent by The Gambia. Legal restrictions in The Gambia followed the PIC policy, so legally the government should be approving and regulating the import and sales of these pesticides, but this was not occurring.

Additional nonpesticide components also were identified in the samples. The majority of these additional substances were carrying agents, but the analysis did show individual samples that contained nonpesticide components. Compounds found in materials sold as pesticides included chlorphenamine (antihistamine), methanamine (antibiotic), vitamin E, and mebendazole (drug to treat tapeworms).

The type of pesticide formulation can affect transportation, storage, and use. The majority of the pesticides used were powdered (59.1\%). Powdered formulations were preferred by vendors due to easy repacking into small, plastic bags. Liquid pesticides made up 20.9\%, granular pesticides made up $15.5 \%$, and solids in the form of pellets, discs, or chalk-like products made up $9.1 \%$ of the pesticide samples. 
TABLE 4: Identities of 168 pesticide components collected from local street markets (see text for analysis conditions).

\begin{tabular}{|c|c|c|c|c|c|}
\hline Pesticides identified* & WHO classification & Use & Chemical class & Number of samples & $\%$ \\
\hline Chlorpyrifos & Class II & $\begin{array}{l}\text { Acaricide, } \\
\text { insecticide, } \\
\text { nematicide }\end{array}$ & Organophosphate & 25 & 14.9 \\
\hline Endosulfans & Class II & $\begin{array}{l}\text { Acaricide, } \\
\text { insecticide }\end{array}$ & Organochlorine & 24 & 14.3 \\
\hline Carbofuran & Class IB & $\begin{array}{l}\text { Acaricide, } \\
\text { insecticide, } \\
\text { nematicides }\end{array}$ & Carbamates & 22 & 13.1 \\
\hline Fenitrothion & Class II & Insecticide & Organophosphate & 22 & 13.1 \\
\hline$\underline{\text { Lindane }}$ & Class II & $\begin{array}{l}\text { Acaricide, } \\
\text { insecticide, } \\
\text { rodenticide }\end{array}$ & Organochlorine & 14 & 8.3 \\
\hline Propoxur & Class II & $\begin{array}{l}\text { Acaricide, } \\
\text { insecticide }\end{array}$ & Carbamate & 12 & 7.1 \\
\hline Deltamethrin & Class II & Insecticide & Pyrethroid & 6 & 3.7 \\
\hline Tetramethrin & Minimal hazard in normal use & Insecticide & Pyrethroid & 5 & 3.0 \\
\hline Dimethoate & Class II & $\begin{array}{l}\text { Acaricide, } \\
\text { insecticide, } \\
\text { nematicide }\end{array}$ & Organophosphate & 4 & 2.4 \\
\hline Chlorobenzilate & Considered discontinued for pesticide use & Acaricide & Organochlorine & 3 & 1.8 \\
\hline Cypermethrin & Class II & $\begin{array}{l}\text { Acaricide, } \\
\text { insecticide }\end{array}$ & Pyrethroid & 3 & 1.8 \\
\hline Methylparathion & Class IA & Insecticide & Organophosphate & 3 & 1.8 \\
\hline Sulfur & Minimal hazard in normal use & $\begin{array}{l}\text { Acaricide, } \\
\text { fungicide }\end{array}$ & Unclassified & 3 & 1.8 \\
\hline Dicofol & Class III & Acaricide & Organochlorine & 2 & 1.2 \\
\hline Malathion & Class III & $\begin{array}{l}\text { Acaricide, } \\
\text { insecticide }\end{array}$ & Organophosphate & 2 & 1.2 \\
\hline Monocrotophos & Class IB & $\begin{array}{l}\text { Acaricide, } \\
\text { insecticide }\end{array}$ & Organophosphate & 2 & 1.2 \\
\hline Napthalene & Considered discontinued for pesticide use & $\begin{array}{l}\text { Fumigant } \\
\text { insecticide }\end{array}$ & Unclassified & 2 & 1.2 \\
\hline Profenofos & Class II & Insecticide & Organophosphate & 2 & 1.2 \\
\hline Carbaryl & Class II & $\begin{array}{l}\text { Acaricide, } \\
\text { insecticide }\end{array}$ & Carbamate & 1 & 0.6 \\
\hline Metolachlor & Class III & Herbicide & Chloroacetanilide & 1 & 0.6 \\
\hline Chlorfenson & Class III & Acaricide & Unclassified & 1 & 0.6 \\
\hline Pirimiphos methyl & Class III & $\begin{array}{l}\text { Acaricide, } \\
\text { insecticide }\end{array}$ & Organophosphate & 1 & 0.6 \\
\hline Tetradifon & Minimal hazard in normal use & Acaricide & Unclassified & 1 & 0.6 \\
\hline Not identified & & Unknown & Unknown & 7 & 4.2 \\
\hline
\end{tabular}

* Italicized pesticide components are severely restricted in the United States. Boldfaced pesticide components are banned in the United States.

Underlined pesticide components are on the United Nations PIC list.

The four villages Brikama, Kuntaur, Farafenni, and Serrekunda represent the primary street markets where pesticide purchase for community use occurs (Table 6). Organophosphates were the most common types of pesticides discovered in all markets except in Brikama, where a slightly higher percentage of organochlorines were collected. Kuntaur had the largest percentage of samples that were not identified as among the four major pesticide classes. Nearly all of the vendors repackaged pesticides for resale usually without providing labels.

\section{Discussion}

This study showed that there were a wide variety of pesticides in circulation in The Gambia, many of which are considered unsafe for use by the United States and WHO. Identifying the 
TABLe 5: Hazard classification of identified pesticide components.

\begin{tabular}{lcc}
\hline & $\begin{array}{c}\text { Number of } \\
\text { pesticide } \\
\text { components }\end{array}$ & $\begin{array}{c}\text { Percent of all } \\
\text { pesticide } \\
\text { components }\end{array}$ \\
\hline $\begin{array}{l}\text { Not an insecticide } \\
\text { Pesticides restricted in the }\end{array}$ & 39 & 3.1 \\
$\begin{array}{l}\text { USA } \\
\text { Pesticides banned in the USA }\end{array}$ & 30 & 24.2 \\
$\begin{array}{l}\text { Pesticides classified hazardous } \\
\text { by World Health Organization }\end{array}$ & 27 & 18.6 \\
$\begin{array}{l}\text { UN prior informed consent } \\
\text { pesticide }\end{array}$ & 22 & 16.8 \\
\hline
\end{tabular}

sources, types, and potential hazards of dangerous pesticides was complicated by the fact that pesticides sold on the street were rarely labeled so that the identities of the pesticides were not known, often not even by the pesticide vendor. The high percentage of multiple pesticide components is likely due to the common practice of mixing together leftover pesticides. Most pesticide storage containers were unlabeled, so when volumes were low there was no deterrent to combining different pesticide formulations together and selling these mixtures.

The high percentage of pesticide components identified that are considered severely restricted pesticides in the United States is a concern because those pesticides are hazardous and should be applied only for specific uses and only by individuals with advanced training. Individuals purchasing these pesticides for home use most often were not properly trained, and the pesticides were inappropriate and potentially dangerous for home use. The banned pesticides are not allowed for use in the United States for health or environmental reasons. These pesticides, as well as those classified as hazardous by WHO and PIC, were clearly inappropriate for home use, posing potential safety risks for individuals and their families. The identification of twenty-two ingredients covered under the United Nations prior informed consent rules illustrates the lack of effective regulations as these were pesticides that should be fully regulated by the Gambian government for both distribution and use. A portion of the samples identified were not even insecticides as claimed by the vendor. Though not presenting exposure risks, these random substances are ineffective in eliminating insect vectors and could provide a false sense of protection within the homes.

The results of this study are a reminder of the fluid movement of dangerous pesticides within African countries. The high-risk pesticides listed by the EPA and WHO require specialized experience and knowledge that does not exist with the individuals purchasing these pesticides at the markets. Our results indicate that regulations regarding the importation of pesticides were ineffective. The Gambia has limited resources and personnel to commit to monitoring its border, which makes it difficult to prevent the large influx of unregulated pesticides across the border from Senegal. The most effective way to regulate the movement of pesticides and protect the population from toxic pesticide exposures may be through the education and regulation of the pesticide vendors themselves. Toxic pesticides are a risk not only to vendors and individual pesticide applicators but also could present significant exposure risks for families by increasing the risk of pesticide exposure for vulnerable populations such as children and pregnant women.

Though minimal information could be discovered about where the pesticides were originally produced, an important finding was that even the labeled pesticides were written in a variety of world languages, limiting the effectiveness of labels at times in communicating health risks to both vendors and customers. These findings correspond with pesticide vendors who that claim illegal smuggling of pesticides across borders is rampant and introduces a wide variety of unregulated pesticides into Gambian markets. A limitation of this study is that samples were not systematically collected from all markets in The Gambia and the results are not representative to the entire population.

The government has specific guidelines discussing the importation of pesticides and what is allowed within The Gambia. Awareness that some pesticides are illegal and all pesticides should be sold with labels could be communicated to pesticide vendors. Public health officers could inspect pesticide vendors on market day to enforce that all pesticides are being sold with labels (even if hand written) as an initial deterrent. That would be a feasible course of action that could encourage cooperation with current pesticide policies.

\section{Conclusions}

There have always been public health concerns regarding the sale of hazardous pesticides in developing countries. This is the first study in Africa to quantitatively sample pesticides where they are commonly sold and identify unknown pesticides to determine the exposure health risks associated with the pesticides in circulation. The results show significant percentages of the pesticides in use in The Gambia were extremely hazardous and should not be used by untrained individuals and without proper protection equipment. Even worse, these pesticides were commonly being sold without safety labels, so there was no method for a customer to know the difference between use of a less hazardous pesticide such as deltamethrin versus a highly toxic pesticide banned throughout the world. The results of this research can further discussions about enforcement of pesticide importation laws and the revision of current pesticide regulations to target major issues that could minimize pesticide exposure risks and protect human health.

\section{Disclaimer}

The mention of any company or product does not constitute an endorsement by the Centers for Disease Control and Prevention. The findings and conclusions in this paper are those of the authors and do not necessarily represent the views of the National Institute for Occupational Safety and Health. 
TABLE 6: Pesticide street markets targeted for sample collection and pesticide classes identified.

\begin{tabular}{|c|c|c|c|c|c|c|c|}
\hline \multirow{2}{*}{ Market } & \multirow{2}{*}{ City population } & \multirow{2}{*}{ Percent of pesticides labeled } & \multicolumn{5}{|c|}{ Pesticide classes identified } \\
\hline & & & $\% \mathrm{OP}$ & $\%$ OC & $\% \mathrm{C}$ & $\% \mathrm{P}$ & $\%$ Other \\
\hline Kuntaur & 7,237 & 9.4 & 30.8 & 10.3 & 12.8 & 23.0 & 10.3 \\
\hline Farafenni & 42,434 & 16.7 & 37.7 & 26.1 & 23 & 6.6 & 3.3 \\
\hline Brikama & 88,870 & 5.6 & 34.0 & 35.8 & 22.6 & 1.9 & 1.9 \\
\hline Serrekunda & $1,205,034$ & 8.3 & 30.0 & 10.0 & 30.0 & 0 & 20 \\
\hline
\end{tabular}

OP: Organophosphate pesticides.

OC: Organochlorine pesticides.

C: Carbamate pesticides.

P: Pyrethroid pesticides.

\section{Acknowledgments}

The authors would like to thank the University of Iowa Great Plains Center for Agricultural Health and the University of Iowa Educational and Research Center for their financial support.

\section{References}

[1] C. Guinovart, M. M. Navia, M. Tanner, and P. L. Alonso, "Malaria: burden of disease," Current Molecular Medicine, vol. 6, no. 2, pp. 137-140, 2006.

[2] D. J. Gubler, "Resurgent vector-borne diseases as a global health problem," Emerging Infectious Diseases, vol. 4, no. 3, pp. 442-450, 1998.

[3] J. Jeyarathnam, "Acute pesticide poisoning: a major global health problem," World Health Statistics Quarterly, vol. 43, no. 3, pp. 139-144, 1990.

[4] J. E. García, "Acute pesticide poisoning: human and economic costs," Revista Panamericana de Salud Publica/Pan American Journal of Public Health, vol. 4, no. 6, pp. 383-387, 1998.

[5] L. S. Azaroff and L. M. Neas, "Acute health effects associated with nonoccupational pesticide exposure in rural El Salvador," Environmental Research, vol. 80, no. 2 I, pp. 158-164, 1999.

[6] M. M. M. Beshwari, A. Bener, A. Ameen, A. M. Al-Mehdi, H. Z. Ouda, and M. A. H. Pasha, "Pesticide-related health problems and diseases among farmers in the United Arab Emirates," International Journal of Environmental Health Research, vol. 9, no. 3, pp. 213-221, 1999.

[7] M. Maroni, A. Fait, and C. Colosio, "Risk assessment and management of occupational exposure to pesticides," Toxicology Letters, vol. 107, no. 1-3, pp. 145-153, 1999.

[8] World Health Organization, Public Health Impact of Pesticides Used in Agriculture, WHO, Geneva, Switzerland, 1990.

[9] J. M. Bertolote, A. Fleischmann, M. Eddleston, and D. Gunnell, "Deaths from pesticide poisoning: a global response," British Journal of Psychiatry, vol. 189, pp. 201-203, 2006.

[10] D. J. Ecobichon, "Pesticide use in developing countries," Toxicology, vol. 160, no. 1-3, pp. 27-33, 2001.

[11] F. Konradsen, W. Van Der Hoek, D. C. Cole et al., "Reducing acute poisoning in developing countries-options for restricting the availability of pesticides," Toxicology, vol. 192, no. 2-3, pp. 249-261, 2003.

[12] M. B. S. Canteh, Registar, Hazardous Chemicals and Pesticides, NEA, Banjul, The Gambia.
[13] Pesticide Africa Network (PAN), "Toxicity, ecological toxicity, and regulatory information,” 2007, http://www.pesticideinfo.org.

[14] Pesticide Action Network in North America (PANNA), "Chloropyrifos Facts," 2007, http://www.panna.org/resources/ documents/factsheetChlorpyrifos. 


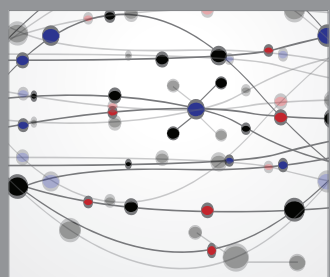

The Scientific World Journal
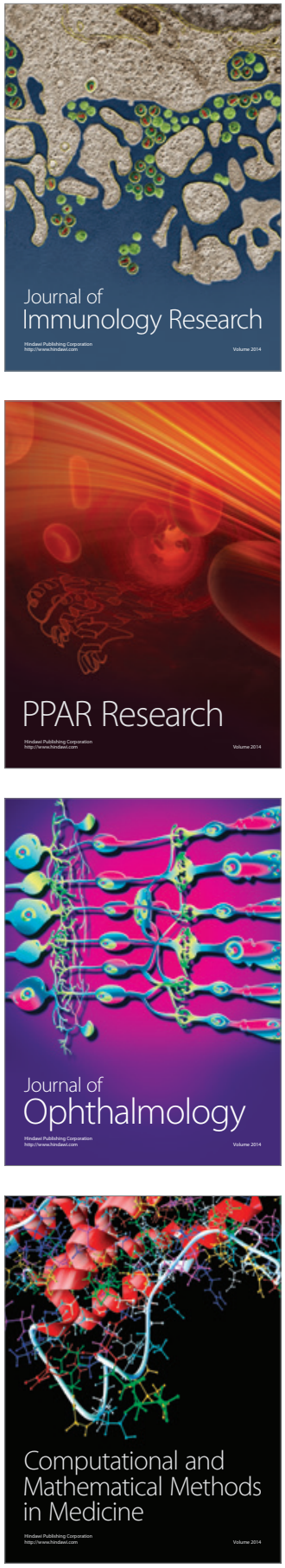

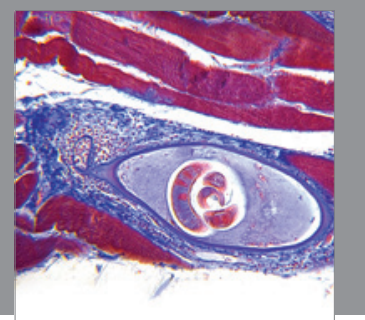

Gastroenterology

Research and Practice
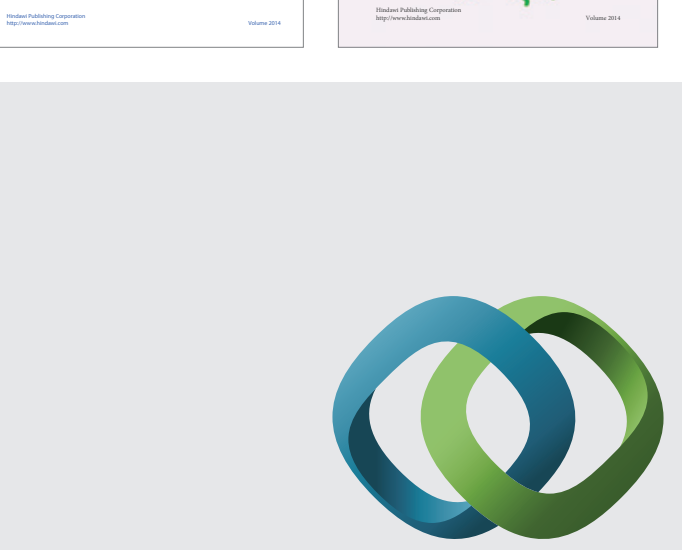

\section{Hindawi}

Submit your manuscripts at

http://www.hindawi.com
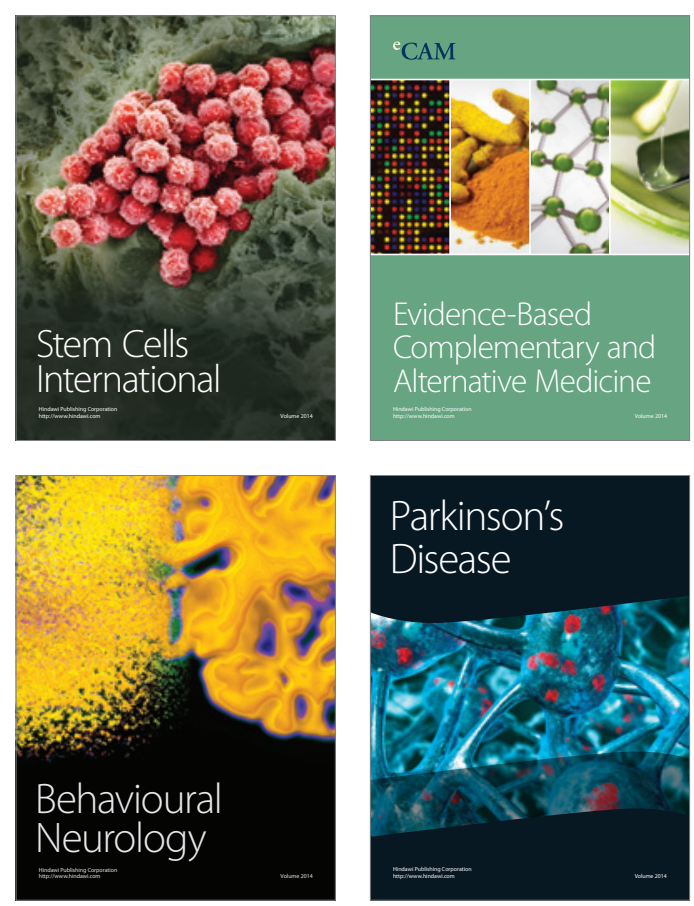

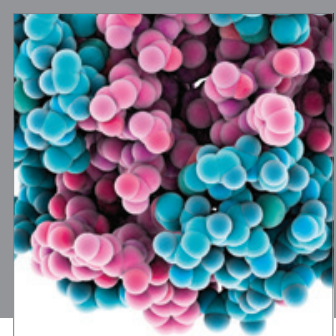

Journal of
Diabetes Research

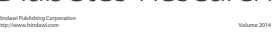

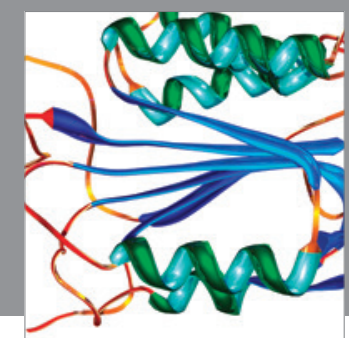

Disease Markers
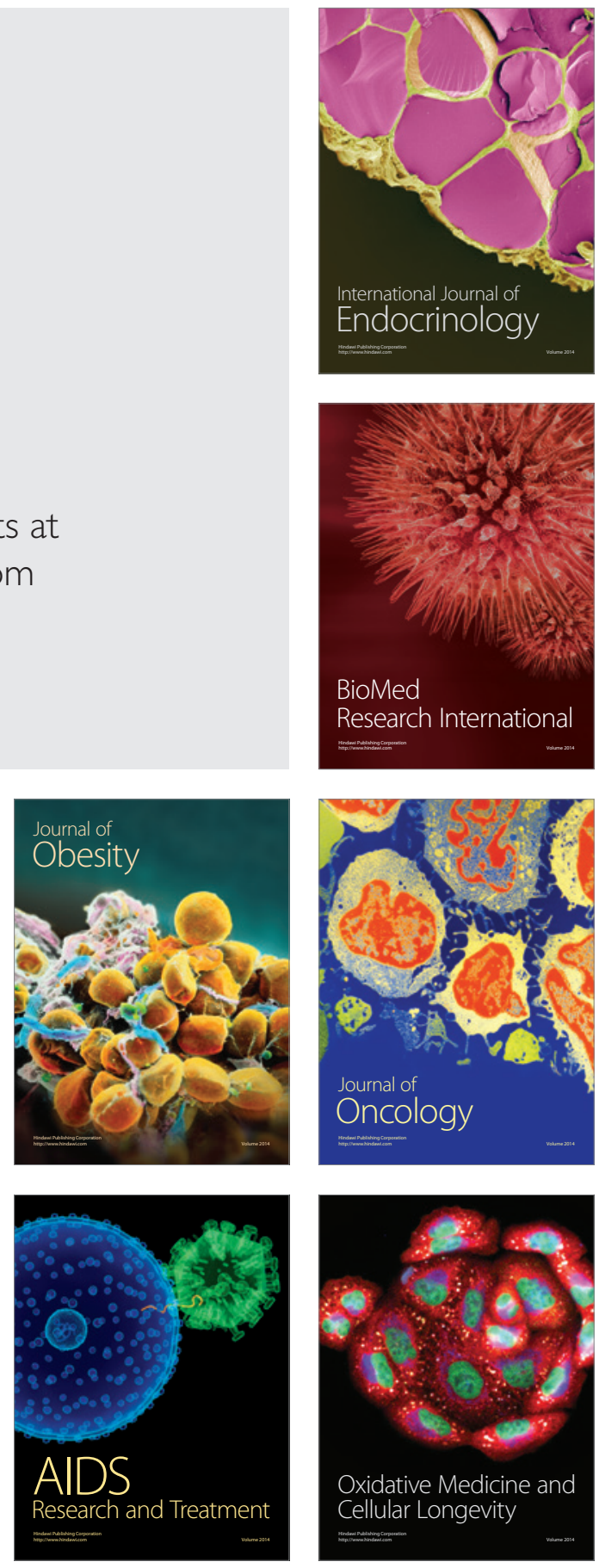